For personal use only. Not to be reproduced without permission of the publisher (editorial@gabi-journal.net).

\title{
Challenges to generic medicines utilization in Yemeni healthcare
}

\section{system}

\author{
Saleh Karamah AL-Tamimi'1,2, BPharm, MPharm (ClinPharm); Mohamed \\ Azmi Hassali ${ }^{1}$ BPharm(Hons), MPharm (ClinPharm), PhD; Alian A \\ Alrasheedy', BPharm(Hons), MPharm(Clin), BCPS
}

Generic medicines are promoted in many countries as an essential part of the healthcare system. However, in Yemen, there are many challenges to the utilisation of generic medicines. Currently, there is no national level policy to enhance or promote generic medicines use. In addition, other challenges to the use of generic medicines in Yemen including negative perceptions and availability of counterfeit medicines are highlighted in this brief report.

Keywords: Challenges, consumers, generic medicines, healthcare professionals, Yemen

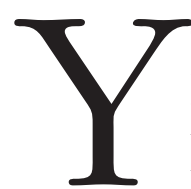

emen faces several challenges in most aspects of life. Current challenges include the high unemployment rate (more than $50 \%$ of the population), a low level of education, high population growth, and limited access to healthy water and appropriate sanitation. In addition, it is estimated that about two million children are suffering from chronic malnutrition. Furthermore, the continuous political conflict and clashes worsen the situation and weaken the healthcare system, leading to the ongoing humanitarian crises in this low income country $[1,2]$.

The healthcare system in Yemen confronts many obstacles. The annual health expenditure in Yemen (US\$40 per capita) is among the lowest in the world.

Access to medicines is defined as the timely use of standard medicines according to needs and it should be accessible and available in the region, as well as affordable and acceptable by the patients [3].

Moreover, the current status of access to medicines and health services in Yemen is in an alarming state. Currently, about $70 \%$ of the population live in remote areas where they lack access to medicines and basic health services [4]. Public and private health services are mainly available in the capital and urban cities and patients have to pay the consultation fees, the cost of diagnostic tests and the cost of medicines.

According to World Health Organization, a generic drug is 'a pharmaceutical product, usually intended to be interchangeable with an innovator product that is manufactured without a licence from the innovator company and marketed after the expiry date of the patent or other exclusive rights' [5]. The use of generic medicines is advocated by many governments and third party payers as a mean to confront the escalation of medicine expenditure [6]. The generic medicines are usually cheaper and their prices were estimated to be 20-90\% lower than the innovator original medicines $[6,7]$. In fact, the wide use of generic medicines can lead to substantial savings. For example, a recent study showed that generic medicines saved approximately US\$1 trillion

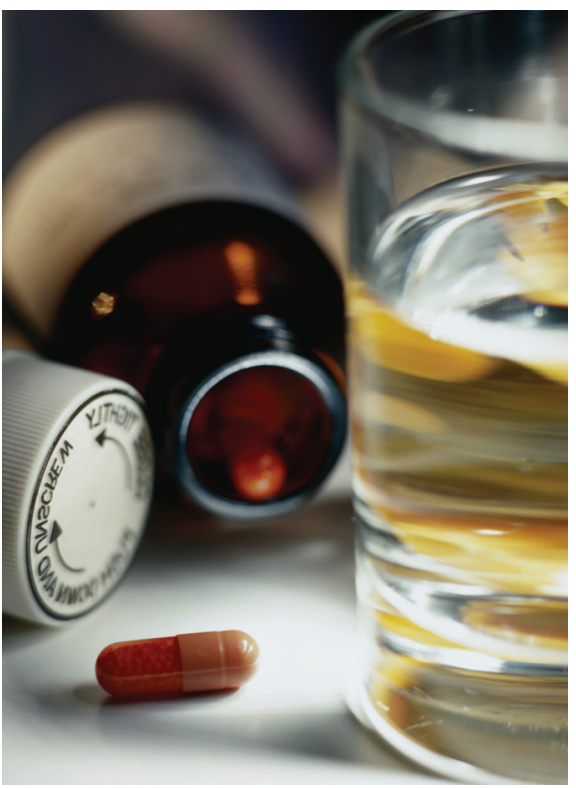

in the last decade (2002 through 2011) in the US [8]. Thus, the wide use of generic medicines is essential to enhance the access to essential medicines particularly in low and middle income countries [7] and the savings that are achieved could be allocated to get the more expensive patented medicines [9]. Furthermore, generic medicines could improve patients' adherence to medicines in general and patients with poly-pharmacy in particular [10]. Besides that, the competition between the originator and the generic medicines manufacturers can lead to constant supply of medicines in the market, price reduction of medicines and also encourage innovation by original innovators manufacturers [7].

Therefore, the use of generic medicines provides an opportunity for diminishing healthcare funding and an opportunity to save money that can be used to improve the access to medicines and other healthcare services in Yemen. Although the promotion of generic medicines utilisation in Yemen will be of great value, so far there is no national level policy to enhance generic medicine utilisation. Furthermore, we have conducted a research project to evaluate the use of generic medicines in the Yemeni healthcare system and to explore the challenges and facilitators of generic medicine use in Yemen. After obtaining the approval from Ministry of

Author for correspondence: Saleh Karamah AI-Tamimi, BPharm, MPharm (ClinPharm), School of Pharmaceutical Sciences, Universiti Sains Malaysia,

11800 Pulau Pinang, Malaysia

Submitted: 8 February 2013; Revised: 8 March 2013; Accepted: 14 March 2013; Published online first: 27 March 2013 
Health in Yemen, we conducted qualitative studies using face to face in-depth interviews to explore the perceptions of healthcare professionals (physicians and pharmacists) and consumers towards the use of generic medicines. To facilitate the interviewing process, semi-structured interview guides were used to explore the views and get deeper understanding of the interviewees' beliefs and attitudes towards use of generic medicines in Yemen. The interviews were conducted until saturation of the data was achieved. The preliminary study findings revealed some challenges to the use of generic medicines in Yemen. The study findings suggested that although the majority of healthcare professionals accepted generic medicines, in some cases depending on the patient's condition and the socioeconomic factors, most of them had negative perceptions about generic medicines. In addition, the interviewed patients lack sufficient information regarding generic medicines issues and want detailed information about the safety, quality, efficacy and price variation between generic medicines and their counterpart innovators' medicines.

The healthcare professionals raised the issue of counterfeit and smuggled medicines as a major challenge. In fact, it is a serious problem in Yemen. According to the recent report by the Supreme Board for Drugs and Medical Appliances (SBDMA), which is the drug regulatory authority in Yemen, the sub-standard and smuggled medicines are widely available in the country and account for about $60 \%$ of all medicines in the market [11]. In addition to many serious consequences, it is known that the wide presence of counterfeit medicines causes healthcare professionals to lose confidence in the healthcare system [12]. Also, similar to the findings reported in Iraq [13], healthcare professionals in Yemen stated that it is difficult to differentiate between counterfeit and generic medicines in the market.
Thus, physicians are reluctant to prescribe generic medicines because of these counterfeit medicines. Therefore, the SBDMA and the Ministry of Health should enforce the law and prevent the entry of such medicines.

In conclusion, the quality use of generic medicines needs to be promoted in Yemen. At the regulatory authority level, only generic medicines of proven quality and efficacy should be available in the market and, accordingly, healthcare professionals (both physicians and pharmacists) should be educated and encouraged to recommend generic medicines to their patients.

\section{Funding sources}

This research received no specific grant from any funding agency in the public, commercial, or not-for-profit sectors.

Competing interests: The authors declare that they have no conflicts of interest to disclose.

Provenance and peer review: Not commissioned; externally peer reviewed.

\section{Authors}

Saleh Karamah AL-Tamimi ${ }^{1,2}$, BPharm, MPharm (ClinPharm)

Mohamed Azmi Hassali ${ }^{1}$, BPharm (Hons), MPharm (ClinPharm), PhD

Alian A Alrasheedy ${ }^{1}$, BPharm (Hons), MPharm(Clin), BCPS

${ }^{1}$ School of Pharmaceutical Sciences, Universiti Sains Malaysia, 11800 Pulau Pinang, Malaysia

${ }^{2}$ Faculty of Pharmacy, University of Aden, Aden, Yemen

Authors are responsible for English language editing of this manuscript.

\section{References}

1. Burki TK. Yemen's hunger crisis. Lancet. 2012; 380(9842):637-8
2. Meleigy M. Yemen conflict takes its toll on civilians. Lancet. 2010;375(9711):269-70.

3. Peters DH, Garg A, Bloom G, Walker DG, Brieger WR, Hafizur Rahman M. Poverty and access to health care in developing countries. Ann N Y Acad Sci. 2008;1136:161-71. doi:10.1196/ annals. 1425.011

4. Holst J, Gericke CA. Healthcare financing in Yemen. Intl J Health Plan Manage. 2012;27(3): 198-225. doi:10.1002/hpm.2107

5. World Health Organization [homepage on the Internet]. Glossary of globalization, trade and health terms. 2012 [cited 2013 Mar 8]. Available from: http://www.who.int/trade/glossary/en/

6. Simoens S, De Coster S. Sustaining generic medicines markets in Europe. Journal of Generic Medicines. 2006;3(4):257-68

7. Brems Y, Seville J, Baeyens J. The expanding world market of generic pharmaceuticals. Journal of Generic Medicines: The Business Journal for the Generic Medicines Sector. 2011;8(4):227-39. doi:10.1177/1741134311429752

8. Generic Pharmaceutical Association. GPhA Report. Savings: \$1 trillion over 10 years - generic drug savings in the U.S. J Pharm Health Serv Res. 2012;3(4):229-36. doi:10.1111/jphs.12000

9. King DR, Kanavos P. Encouraging the use of generic medicines: implications for transition economies. Croat Med J. 2002;43(4): 462-9.

10. Goldman D, Joyce GF, Zheng Y. Prescription drug cost sharing: associations with medication and medical utilization and spending and health. JAMA. 2007;298(1):61-9.

11. Supreme Board of Drugs and Medical Appliances. Annual reports of the Supreme Commission for Drugs and Materials Appliances. The final report for the year 2011. Available from: www. sbdye.org

12. Counterfeit drugs: a growing global threat. The Lancet. 2012;379(9817):685. doi:10.1016/S01406736(12)60289-X

13. Sharrad AK, Hassali MA, Shafie AA. Generic medicines: perceptions of physicians in Basrah, Iraq. Australas Med J. 2009;1(8):58-64. doi:10.4066/ AMJ.2009.82

DOI: 10.5639/gabij.2013.0202.017

Copyright (c) 2013 Pro Pharma Communications International 